\title{
SELETIVIDADE DE INSETICIDAS A ORIUS INSIDIOSUS $\left({ }^{1}\right)$
}

\author{
FABRÍCIA ZIMERMANN VILELA TORRES $(2,3)$; GERALDO ANDRADE CARVALHO $\left({ }^{2 * 3}\right)$; \\ JANDER RODRIGUES DE SOUZA $\left({ }^{2,3}\right)$; LUIZ CARLOS DIAS ROCHA $\left({ }^{2,3}\right)$
}

\begin{abstract}
RESUMO
A utilização de produtos fitossanitários seletivos a inimigos naturais é importante para o sucesso de programas de manejo integrado de pragas em agroecossistemas. Objetivou-se investigar efeitos letais e subletais de inseticidas empregados para o controle de pragas da roseira sobre ovos e ninfas de quinto ínstar de Orius insidiosus (Say) Hemiptera: Anthocoridae, em condições laboratoriais. Formulações comerciais dos seguintes inseticidas foram diluídas em água destilada (concentração em g i.a./100 ml): endosulfam $(0,021)$, formetanato $(0,04)$, espinosade $(0,0144)$ e deltametrina $(0,0008)$. O tratamento testemunha foi somente com água destilada. Os bioensaios foram mantidos em câmara climática a $25 \pm 2{ }^{\circ} \mathrm{C}$, UR de $70 \pm 10 \%$ e fotofase de 12 horas. Ovos do predador colocados em hastes de picão-preto (Bidens pilosa L.) foram imersos nas caldas inseticidas por cinco segundos. As ninfas de quinto ínstar do predador foram tratadas com os inseticidas em torre de Potter. O efeito total dos inseticidas foi estimado e enquadrados em classes toxicológicas de acordo com a IOBC. O inseticida deltametrina foi nocivo a ovos e ninfas de quinto ínstar de O. insidiosus; endosulfam, formetanato e espinosade foram levemente nocivos. Endosulfam e formetanato não afetaram negativamente as características reprodutivas de fêmeas oriundas de ovos tratados. Endosulfam e espinosade reduziram o número de ovos colocados por fêmeas oriundas de ninfas de quinto ínstar que receberam tratamento, e espinosade afetou negativamente a viabilidade desses ovos.
\end{abstract}

Palavras-chave: seletividade, manejo integrado de pragas, controle biológico.

\section{ABSTRACT SELECTIVITY OF INSECTICIDES TO ORIUS INSIDIOSUS}

The use of selective pesticides to natural enemies is important for the success of integrated pest management programs. The objective of this study was to investigate lethal and sublethal effects of some insecticides, used to control pests in rose crops, on eggs and fifth instar-nymphs of Orius insidiosus (Say) under laboratory conditions. Commercial formulations of the following insecticides were diluted in distilled water (concentration in $\mathrm{g}$ a.i./100 ml): endosulfan $(0.021)$, formetanate $(0.04)$, spinosad $(0.0144)$ and deltamethrin (0.0008). Distilled water was used as control. The tests were carried out in climatic chamber at $25 \pm 2^{\circ} \mathrm{C}, \mathrm{RH}$ of $70 \pm 10 \%$ and $12 \mathrm{~h}$-photophase. The eggs of the predator laid on Bidens pilosa L. stems were treated by dipping the stems containing eggs into insecticide solutions for five seconds. Fifth instar-nymphs were treated with the insecticides using a Potter spray tower. The total effect of the insecticides was estimated and they were classified according to the toxicity categories proposed by the IOBC. Deltamethrin was harmful and, endosulfan, formetanate and spinosad were slightly harmful to eggs and fifth instar-nymphs of $O$. insidiosus. Endosulfan and formetanate did not affect negatively the reproductive characteristics of the females originated from treated eggs. Endosulfan and spinosad reduced the number off eggs laid by the females originated from the treated fifth instar-nymphs, and spinosad affected negatively the viability of these eggs.

Key words: selectivity, integrated pest management, biological control.

$\left({ }^{1}\right)$ Recebido para publicação em 24 de outubro de 2005 e aceito em 13 de fevereiro de 2007.

$\left({ }^{2}\right)$ Departamento de Entomologia, Universidade Federal de Lavras, Caixa Postal 3037, 37200-000 Lavras, Brasil. E-mail: fabriciazimermann@yahoo.com.br; gacarval@ufla.br (*) Autor correspondente.

$\left({ }^{3}\right)$ Bolsista do CNPq. 


\section{INTRODUÇÃO}

No Brasil, existem cerca de 7.600 produtores de flores, distribuídos em 1.500 municípios, ocupando uma área de 9.000 hectares (KIYUnA et al., 2002). No plantio de roseiras destacam-se os municípios de Atibaia e Holambra, no Estado de São Paulo, e Barbacena, Munhoz, Antônio Carlos, Andradas e Senador Amaral, em Minas Gerais (BARBosa et al., 2005; Landgraf e Paiva, 2005).

$\mathrm{Na}$ cultura da roseira, as pragas de maior ocorrência são ácaros, pulgões, tripes, cochonilhas e besouros, controladas na maioria das vezes por produtos químicos (SILVA, 1987; LARSON, 1992), que podem causar desequilíbrios biológicos e contaminação ambiental.

Entre as alternativas potenciais de controle de tripes em roseira, cita-se o uso de percevejos predadores do gênero Orius (Wolff) (Hemiptera: Anthocoridae), insetos pequenos e ágeis, presentes em diversos agroecossistemas, alimentando-se também de ácaros, afídeos, ovos e pequenas lagartas de lepidópteros (ElLington et al., 1998; BuEno, 2000). Porém, para que esses percevejos possam demonstrar sua máxima potencialidade como predadores, é importante o uso de inseticidas seletivos nas áreas onde se deseja realizar o controle biológico de pragas com esses inimigos naturais. Assim, sua preservação em cultivos agrícolas pode contribuir para a redução do número de aplicações de inseticidas, proporcionando maior economia e menor impacto ao ambiente.

Estudos a respeito dos efeitos de pesticidas sobre $O$. insidiosus estão em fase inicial no Brasil, destacando-se trabalhos de CARvalHo et al. (2002), MorAis et al. (2003) e RochA et al. (2006), que buscaram avaliar, além da mortalidade causada por produtos químicos, seu efeito sobre a reprodução desse predador.

Em virtude da necessidade de se conhecer mais a respeito da toxicidade de pesticidas para $O$. insidiosus, objetivou-se, neste estudo, investigar em laboratório o efeito letal dos inseticidas endosulfam, formetanato, espinosade e deltametrina sobre ovos e ninfas de quinto ínstar desse predador e o efeito subletal em sua reprodução.

\section{MATERIAL E MÉTODOS}

Avaliaram-se os efeitos dos inseticidas (em g i.a./100 ml): endosulfam $(0,021)$ (Endosulfan Fersol ${ }^{\circledR}$ $350 \mathrm{CE})$, formetanato $(0,04)$ (Dicarzol ${ }^{\circledR} 500$ PS), espinosade $(0,0144)\left(\right.$ Tracer $^{\circledR} 480$ SC) e deltametrina
$(0,0008)$ (Decis $\left.{ }^{\circledR} 25 \mathrm{CE}\right)$, sobre $O$. insidiosus. Os produtos e as concentrações avaliados são utilizados por produtores de roseira em municípios do Sul de Minas Gerais. O tratamento-testemunha foi constituído apenas de água destilada.

\subsection{Efeito dos inseticidas sobre ovos de O. insidiosus}

Utilizaram-se 200 ovos com até 24 horas de idade, depositados em hastes de picão-preto por adultos da criação de laboratório, pertencentes à sexta geração. As hastes foram imersas nas caldas dos inseticidas por cinco segundos e dispostas em placas de Petri de $10 \mathrm{~cm}$ de diâmetro, com suas bases envolvidas por chumaço de algodão umedecido em água destilada, para evitar sua dessecação. As placas foram fechadas com filme plástico de cloreto de polivinila (PVC) e mantidas em câmara climática a 25 $\pm 2{ }^{\circ} \mathrm{C}$, UR de $70 \pm 10 \%$ e fotofase de 12 horas. As ninfas recém-eclodidas foram individualizadas em placas de Petri de $5 \mathrm{~cm}$ de diâmetro, contendo chumaço de algodão umedecido em água destilada para manutenção da umidade e alimentadas ad libitum, a cada 48 horas, com ovos inviabilizados de Anagasta kuehniella (Zeller).

O delineamento experimental utilizado foi inteiramente ao acaso, com cinco tratamentos (quatro inseticidas e testemunha) e quatro repetições, sendo cada parcela constituída por 10 ovos do predador. Avaliaram-se a viabilidade dos ovos, a duração do período embrionário e de cada estádio ninfal e a sobrevivência das ninfas de primeiro, segundo, terceiro, quarto e quinto ínstares oriundas desses ovos tratados.

Os dados de viabilidade dos ovos tratados e da duração dos ínstares subseqüentes foram submetidos à análise de variância sem transformação de dados. Quanto à sobrevivência das ninfas oriundas de ovos tratados, os dados foram submetidos à análise de variância em esquema fatorial $5 \times 5$ (tratamentos $\times$ ínstares) e as médias de sobrevivência de cada ínstar foram transformadas para arco-seno $\sqrt{x / 100}$.

\subsection{Efeito dos inseticidas sobre a reprodução de espécimes oriundos de ovos tratados de $O$. insidiosus}

Para os tratamentos em que houve produção de adultos, logo após sua emergência, foram separados um mínimo de seis casais por tratamento, conforme recomendação da "International Organization for Biological and Integrated Control of Noxious Animals and Plants (IOBC)" (Franz et al., 1980). Cada casal foi colocado em placa de Petri de 5 $\mathrm{cm}$ de diâmetro, contendo ovos inviabilizados de $A$. 
kuehniella para sua alimentação e algodão umedecido. As placas foram fechadas com filme plástico de PVC e mantidas em câmara climática regulada conforme descrito anteriormente. Os casais receberam diariamente uma haste de inflorescência de picãopreto envolvida na base por chumaço de algodão umedecido em água, para oviposição, por um período de 24 horas, e alimento a cada 48 horas. Diariamente, as hastes foram substituídas e registrado o número de ovos depositados por haste. As hastes contendo os ovos foram condicionadas em tubos de vidro de 8,5 $\mathrm{cm}$ de comprimento $\times 2,5 \mathrm{~cm}$ de diâmetro. Após sete dias foi realizada a avaliação da viabilidade de ovos, sendo considerados viáveis aqueles com opérculos abertos.

O experimento com os adultos provenientes de ovos tratados foi realizado em delineamento inteiramente ao acaso, com três tratamentos (dois inseticidas e testemunha) e número mínimo de seis repetições, sendo cada uma composta por um casal de $O$. insidiosus. O número de ovos depositados diariamente e o total durante os primeiros 15 dias de vida dos adultos foram determinados, bem como sua viabilidade.

Para se proceder à análise de variância, os dados referentes ao número diário e total de ovos depositados durante os primeiros 15 dias de vida dos adultos foram transformados para $\sqrt{x+1}$, e os referentes à viabilidade dos ovos foram analisados sem transformação.

\subsection{Efeito dos inseticidas sobre ninfas de quinto ínstar}

Ninfas de quinto ínstar de O. insidiosus da criação de laboratório foram agrupadas em placas de Petri de $15 \mathrm{~cm}$ de diâmetro, onde receberam os inseticidas. Para pulverização foi utilizada torre de Potter calibrada a $15 \mathrm{lb} / \mathrm{pol}^{2}$, assegurando uma aplicação de $1,5 \pm 0,5 \mathrm{~mL}$ de calda $/ \mathrm{cm}^{2}$, conforme as recomendações da IOBC “West Palaearctic Regional Section (WPRS)" (STERK et al., 1999).

Após a pulverização, as ninfas foram individualizadas em placas de Petri de $5 \mathrm{~cm}$ de diâmetro, contendo chumaço de algodão umedecido com água destilada, e foram oferecidos como alimento ovos inviabilizados de A. kuehniella em abundância. As placas foram fechadas com filme plástico de PVC e mantidas em câmara climática regulada como descrito anteriormente. O alimento foi oferecido a cada 48 horas e o algodão umedecido a cada 24 horas. O delineamento utilizado foi inteiramente ao acaso, em parcelas subdivididas no tempo, sendo os tratamentos na parcela (quatro inseticidas e testemunha) e quatro repetições, sendo cada uma composta por oito ninfas.

A mortalidade das ninfas foi avaliada 1, 3, 6, 12, 24, 48, 72, 96 e 120 horas após aplicação dos inseticidas, com auxílio de um microscópio estereoscópico (40×), sendo consideradas mortas aquelas que não se moviam ao toque de um pincel. Os dados foram transformados para arco-seno $\sqrt{x}$ e submetidos à análise de variância para comparação dos produtos entre si. Para avaliação dos efeitos dos produtos ao longo do tempo, foi testado o ajuste de uma equação de regressão.

\subsection{Efeito dos inseticidas sobre a reprodução de espécimes provenientes de ninfas tratadas de $O$. insidiosus de quinto ínstar}

Nos tratamentos em que ocorreu emergência de adultos oriundos das ninfas tratadas, os insetos foram agrupados em casais, e o bioensaio foi desenvolvido semelhantemente ao realizado com predadores adultos oriundos de ovos tratados. Utilizou-se delineamento inteiramente ao acaso, com três tratamentos (dois inseticidas e testemunha) e número mínimo de seis repetições, sendo cada uma formada por um casal de O. insidiosus.

Para se proceder às análises de variância, os dados relativos ao número total de ovos depositados durante os primeiros 15 dias de vida dos adultos foram transformados para $\sqrt{x+1}$ e os de viabilidade dos ovos para arco-seno $\sqrt{x / 100}$. Os dados referentes ao número diário de ovos foram analisados sem qualquer transformação. Em todos os bioensaios, nos casos em que o teste F da ANOVA foi significativo, a comparação das médias foi feita pelo teste de Scott-Knott a 5\% de significância (SсOTT e KNOTT, 1974).

Calculou-se o efeito total dos produtos, que foram enquadrados em classes toxicológicas, segundo método proposto pela IOBC (van de VeIRE et al., 1996).

\section{RESULTADOS E DISCUSSÃO}

Nenhum dos compostos afetou a viabilidade dos ovos de $O$. insidiosus, com médias acima de $80 \%$ e média geral de $87,0 \pm 1,29 \%$. Também não foi constatado efeito negativo na duração do período embrionário, que variou de 3,9 a 4,1 dias, para nenhum dos produtos, com média geral de $4,0 \pm 0,02$ dias. 


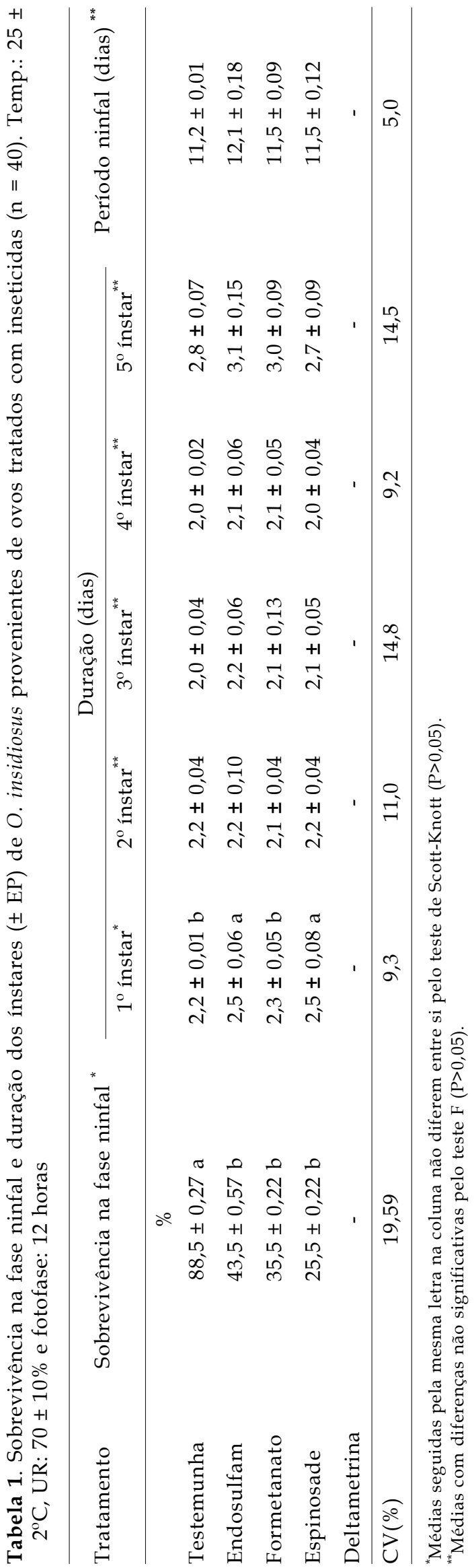

A postura endofítica realizada pelas fêmeas de $O$. insidiosus possivelmente deve impedir maior contato dos ovos com os produtos aplicados, uma vez que apenas o opérculo do ovo fica exposto. Além disso, a espessura do córion, bem como sua composição, provavelmente foi a causa da redução na capacidade de penetração dos inseticidas, permitindo o desenvolvimento embrionário normal. Outros pesquisadores, como SMith e SALKeld (1966), observaram registros de que em Heteroptera, durante o desenvolvimento embrionário, ocorre uma impregnação de cera adicional na superfície interna do córion, conferindo mais uma camada de proteção contra a penetração de substâncias químicas.

Deltametrina não permitiu a sobrevivência de ninfas de $O$. insidiosus recém-eclodidas que, em muitos casos, não conseguiram abandonar os ovos. Endosulfam, formetanato e espinosade diminuíram a sobrevivência de ninfas, não diferindo entre si, com médias de sobrevivência na fase ninfal de $43,5 \%$; $35,5 \%$ e $25,5 \%$, respectivamente (Tabela 1 ). A redução na sobrevivência das ninfas provenientes de ovos tratados ocorreu possivelmente devido a dois fatores: o rompimento da camada cerosa do ovo, no momento da eclosão, o que pode ter gerado uma superfície na qual houve maior contato do inseticida com as ninfas recém-eclodidas; além disso, o contato das ninfas com resíduos dos produtos presentes nas hastes de picãopreto pode ter provocado sua mortalidade.

STERK et al. (2002) estudando os efeitos de alguns inseticidas sobre artrópodes benéficos, verificaram que espinosade $(0,0096 \mathrm{~g}$ i.a. $/ 100 \mathrm{~mL})$ foi inócuo para ninfas de primeiro e segundo ínstares de Orius laevigatus (Fieber), quando entraram em contato com resíduos do inseticida pulverizado sobre folhas de pimentão em casa de vegetação. As divergências de resultados em relação ao presente trabalho, possivelmente ocorreram em vista da utilização de uma espécie diferente do gênero Orius, do ambiente de exposição dos predadores aos compostos e também da menor concentração de espinosade utilizada por esses autores.

Referente à duração dos estádios ninfais, observou-se que endosulfam e espinosade prolongaram a duração do primeiro estádio, alcançando média de 2,5 dias para ambos os compostos (Tabela 1). A duração dos demais ínstares não foi afetada por nenhum dos inseticidas, assim como a duração total do período ninfal.

Quanto às características reprodutivas de $O$. insidiosus avaliadas, endosulfam e formetanato não reduziram o número total de ovos colocados em 15 dias por fêmeas oriundas de ovos tratados, observando-se média geral para os tratamentos de 75,1 $\pm 1,19$ ovos; 
também não houve efeito sobre a viabilidade desses ovos, constatando-se a média para os tratamentos de $58,2 \pm 1,82 \%$ de ovos viáveis. Em virtude do baixo número de insetos sobreviventes nos tratamentos à base de espinosade e deltametrina, não foi possível separar casais suficientes para avaliar seus efeitos sobre as características reprodutivas desse predador.
Calculando o efeito total (E) dos produtos, verificou-se que deltametrina foi o mais tóxico (100\% de mortalidade), sendo categorizado na classe 4 (Tabela 2). Endosulfam, formetanato e espinosade provocaram, respectivamente, mortalidade média de 54,$3 ; 60,0$ e $71,4 \%$ e foram enquadrados na classe 2 (levemente nocivos).

Tabela 2. Mortalidade de O. insidiosus oriundos de ovos tratados, efeito total (E) e classes de toxicidade dos inseticidas ( $\mathrm{n}=40)$. Temp.: $25 \pm 2^{\circ} \mathrm{C}$, UR: $70 \pm 10 \%$ e fotofase: 12 horas

\begin{tabular}{lcccccc}
\hline Tratamentos & $\mathrm{M}\left({ }^{1}\right)$ & $\mathrm{Ma}\left({ }^{2}\right)$ & $\mathrm{N} .{ }^{\circ}$ de casais & N. ${ }^{\circ}$ total de ovos/15 dias & $\mathrm{E}\left({ }^{3}\right)$ & $\mathrm{Classe}\left({ }^{4}\right)$ \\
\cline { 2 - 6 } Testemunha & 12,5 & - & 10 & 74,3 & - \\
Endosulfam & 60,0 & 54,3 & 6 & 72,0 & 55,7 & 2 \\
Formetanato & 65,0 & 60,0 & 6 & 80,8 & 56,4 & 2 \\
Espinosade & 75,0 & 71,4 & - & - & 71,4 & 2 \\
Deltametrina & 100,0 & 100,0 & - & - & 100,0 & 4 \\
\hline
\end{tabular}

$\left({ }^{1}\right)$ Mortalidade acumulada ao longo do desenvolvimento do predador. $\left({ }^{2}\right)$ Mortalidade corrigida pela fórmula de Abbott (1925). $\left({ }^{3}\right)$ Efeito total do produto sobre o predador. $\left({ }^{4}\right)$ Classe de toxicidade segundo a IOBC.

Em se tratando dos efeitos dos inseticidas sobre ninfas de quinto ínstar ao longo do período de avaliações, constatou-se que deltametrina provocou $100 \%$ de mortalidade ao redor de 48 horas; espinosade e formetanato causaram níveis de mortalidade próximos ao longo do tempo, com médias, respectivamente, de 40,6\% e 46,9\%, 120 horas após aplicação, e endosulfam causou apenas $6,3 \%$ de mortalidade no fim das avaliações (Figura 1). Os resultados com deltametrina neste trabalho confirmam aqueles de CONTE (2001), que verificou alta toxicidade desse inseticida para a espécie O. laevigatus.

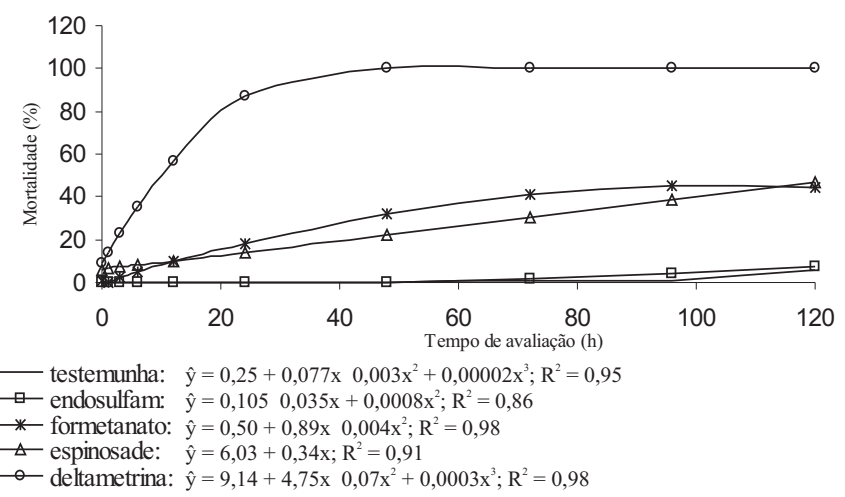

Figura 1. Curvas de mortalidade (\%) ao longo do tempo para ninfas de quinto ínstar de $O$. insidiosus tratadas com inseticidas $(n=32)$. Temp.: $25 \pm 2^{\circ} \mathrm{C}$, UR: $70 \pm 10 \%$ e fotofase: 12 horas.
Embora tenha provocado baixa mortalidade de ninfas de quinto ínstar, endosulfam reduziu o número total de ovos depositados em 15 dias por fêmeas provenientes dessas ninfas tratadas, com média de 14,5 ovos (Tabela 3). Espinosade também causou redução, observando-se média de 11,8 ovos. Quanto à viabilidade desses ovos para endosulfam, a média foi de $44,6 \%$, causando pouco ou nenhum efeito sobre essa característica. Entretanto, tais respostas não estão bem definidas, carecendo de mais estudos para sua melhor compreensão. Já espinosade reduziu a viabilidade de ovos para $24 \%$.

Tabela 3. Número total de ovos em 15 dias e viabilidade $( \pm \mathrm{EP})$ dos ovos de fêmeas oriundas de ninfas de quinto ínstar de $O$. insidiosus tratadas com inseticidas. Temp.: $25 \pm 2{ }^{\circ} \mathrm{C}$, UR: $70 \pm 10 \%$ e fotofase: 12 horas

\begin{tabular}{lcc}
\hline Tratamentos & Número total & Viabilidade \\
\hline Testemunha $(\mathrm{n}=10)$ & $26,0 \pm 2,24 \mathrm{a}$ & $\% 1,9 \pm 2,64 \mathrm{a}$ \\
Endosulfam $(\mathrm{n}=10)$ & $14,5 \pm 1,63 \mathrm{~b}$ & $44,6 \pm 2,53 \mathrm{a}$ \\
Espinosade $(\mathrm{n}=6)$ & $11,8 \pm 3,58 \mathrm{~b}$ & $24,0 \pm 7,06 \mathrm{~b}$ \\
Formetanato & - & - \\
Deltametrina & - & - \\
\hline $\mathrm{CV}(\%)$ & 46,3 & 43,9 \\
\hline
\end{tabular}

Médias seguidas pela mesma letra na coluna não diferem entre si pelo teste de Scott-Knott $(\mathrm{P}>0,05)$.

$\mathrm{n}=$ número de casais. - teste não realizado. 
Tabela 4. Mortalidade de ninfas de quinto ínstar de $O$. insidiosus, efeito total (E) e classe de toxicidade de inseticidas $(\mathrm{n}=32)$; Temp.: $25 \pm 2^{\circ} \mathrm{C}$, UR: $70 \pm 10 \%$ e fotofase: 12 horas

\begin{tabular}{|c|c|c|c|c|c|c|}
\hline Tratamentos & $\mathrm{M}\left({ }^{1}\right)$ & $\mathrm{Ma}\left({ }^{2}\right)$ & N. ${ }^{o}$ de casais & N. ${ }^{o}$ total de ovos/15 dias & $E\left({ }^{3}\right)$ & Classe $\left({ }^{4}\right)$ \\
\hline & \multicolumn{2}{|c|}{$\%$} & & & $\%$ & \\
\hline Testemunha & 6,3 & - & 10 & 26,0 & - & - \\
\hline Endosulfam & 6,3 & 0,0 & 10 & 14,5 & 44,0 & 2 \\
\hline Formetanato & 46,9 & 43,3 & - & - & 43,3 & 2 \\
\hline Espinosade & 40,6 & 36,7 & 6 & 11,8 & 70,9 & 2 \\
\hline Deltametrina & 100,0 & 100,0 & - & - & 100,0 & 4 \\
\hline
\end{tabular}

$\left({ }^{1}\right)$ Mortalidade acumulada ao longo do desenvolvimento do predador. $\left({ }^{2}\right)$ Mortalidade corrigida pela fórmula de Abbott (1925). $\left({ }^{3}\right)$ Efeito total do produto sobre o predador. $\left({ }^{4}\right)$ Classe de toxicidade segundo a IOBC.

Para os tratamentos à base de formetanato e deltametrina não foi possível a formação de número mínimo de casais necessários para avaliação dos efeitos sobre a reprodução. Calculando-se o efeito total (E) dos inseticidas, deltametrina foi considerado nocivo (classe 4), enquanto endosulfam, formetanato e espinosade foram enquadrados na classe 2 , ou seja, levemente nocivos (Tabela 4).

Como se observaram nos inseticidas avaliados diferentes níveis de toxicidade a ovos e ninfas de quinto ínstar de $O$. insidiosus e nenhum deles foi considerado inócuo, tornam-se necessários estudos em condições de casa de vegetação e campo para comprovação final de seus efeitos e possível recomendação em programas de manejo integrado de pragas da roseira que utilizem esse predador como agente de controle biológico.

\section{CONCLUSÕES}

1. O inseticida deltametrina foi nocivo a ovos e ninfas de $O$. insidiosus, enquanto endosulfam, formetanato e espinosade foram levemente nocivos.

2. Com endosulfam e formetanato, as características reprodutivas de fêmeas adultas oriundas de ovos tratados não foram afetadas negativamente.

3. Endosulfam e espinosade reduziram o número de ovos colocados por fêmeas adultas oriundas de ninfas de quinto ínstar que receberam tratamento, e espinosade afetou negativamente a viabilidade desses ovos.

\section{AGRADECIMENTOS}

Ao CNPq, pela concessão de bolsa à Fabrícia Zimermann Vilela Torres.

\section{REFERÊNCIAS}

ABBOTT, W.S. A method of computing the effectiveness of an insecticide. Journal of Economic Entomology, Lanham, v.18, p.265-267, 1925.

BARBOSA, J.G.; GROSSI, J.A.S.; PIVETTA, K.F.L.; FINGER, F.L.; SANTOS, J.M. Cultivo de rosas. Informe Agropecuário, Belo Horizonte, v.26, n.227, p.20-29, 2005.

BUENO, V.H.P. Desenvolvimento e multiplicação de percevejos predadores do gênero Orius Wolff.. In: CONTROLE biológico de pragas: produção massal e controle de qualidade. Lavras: UFLA, 2000. Cap. 5, p. 69-90.

CARVALHO, G.A.; DRUMOND, F.A.; ULHÔA J.L.R.; ROCHA, L.C.D. Efeito de inseticidas sobre Orius insidiosus (Say, 1832) (Hemiptera: Anthocoridae). Ciência e Agrotecnologia, Lavras, v.26, p.52-56, 2002.

CONTE, L. Orius laevigatus (Fieber). Apresenta informações sobre o predador Orius laevigatus. 2001. Disponível em: <http:/ /www.unipd.it/esterni/wwwentom/orius.htm> Acesso em: 16 dez. 2004

ELLINGTON, J.; SOUTHWARD, M.; CARRILLO, T. Association among cotton arthropods. Environmental Entomology, Lanham, v.26, n.5, p.1004-1008, 1998.

FRANZ, J.M.; BOGENSCHÜTZ, H.; HASSAN, S.A.; HUANG, P.; NATON, E.; SUTER H.; VIGGIANI, G. Results of a joint pesticide test programme by the working group: pesticides and beneficial arthropods. Entomophaga, Paris, v.25, n.3, p.231$236,1980$.

KIYUNA, I.; FRANCISCO, V.L.F.S; COELHO, P.J.; CASER, D.V.; ASSUMPÇÃO, R.; ÂNGELO, J.A. A floricultura brasileira no início do século. XXI: o perfil do produtor. Revista Brasileira de Horticultura Ornamental, Campinas, v.8, p.57-76, 2002.

LANDGRAF, P.R.C.; PAIVA, P.D.O. Produção e comercialização de flores em Minas Gerais. Informe Agropecuário, Belo Horizonte, v.26, n.227, p.7-11, 2005. 
LARSON, R.A. (Ed.). Introduction to floriculture. 2.ed. London: Academic, 1992. 636p.

MORAIS, A.A.; CARVALHO, G.A.; MORAES, J.C.; GODOY, M.S.; COSME, L.V. Avaliação de seletividade de produtos fitossanitários utilizados na cultura do crisântemo a adultos de Orius insidiosus (Say, 1832) (Hemiptera: Anthocoridae) em laboratório. Ciência e Agrotecnologia, Lavras, v.27, p.971-977, 2003.

ROCHA, L.C.D.; CARVALHO, G.A.; MOURA, A.P.; COSME, L.V.; VILELA, F.Z. Toxicidade de produtos fitossanitários utilizados na cultura do crisântemo para ovos e ninfas de Orius insidiosus (Say) (Hemiptera: Anthocoridae). Neotropical Entomology, Vacaria, v.35, n.1, p.83-92, 2006.

SCOTT, A.J.; KNOTT, M.A. A cluster analysis method for grouping means in the analysis of variance. Biometrics, Washington, v.30, n.3, p.507-512, 1974.

SILVA, W. Cultivo de rosas no Brasil. 3.ed. São Paulo: Nobel, 1987. 75p.

SMITH, E.H.; SALKELD, E.H. The use and action of ovicides. Annual Review of Entomology, Palo Alto, v.11, p.331-368, 1966.
STERK, G.; HASSAN, S.A.; BAILLOD, M.; BAKKER, F.; BIGLER, F.; BLIIMEL, S.; BOGENSCHIITZ, H.; BOLLER, E.; BROMAND, B.; BRUM, J.; CALIS, J.N.M.; COREMANS-PELSENEER, J.; DUSO, C.; GARRIDO, A.; GROVE, A.; HEIMBACH, U.; HOKKANEN, H.; JACAS, J.; LEWIS, G.; MORETH, L.; POLGAR, L.; ROVERSTI, L.; SAMSE-PETERSEN, L.; SAUPHANOR, B.; SCHAREB, L.; STÁUBLI, A.; TUSET, J.J.; VAINIO, A.; VAN DE VEIRE, M.; VIGGIANI, G.; VIÑUELA, E.; VOGT, H. Results of the seventh joint pesticide testing programme carried out by the IOBC/WPRS - Working Group 'Pesticides and Beneficial Organisms'. BioControl, Netherlands, v.44, p.99-117, 1999.

STERK, G.; HEUTS, F.; MERCK N.; BOCK J. Sensitivity of nontarget arthropods and beneficial fungal species to chemical and biological plant protection products: results of laboratory and semi-field trials. In: INTERNATIONAL SYMPOSIUM ON BIOLOGICAL CONTROL OF ARTHROPODS, 1., 2002, Netherlands. Anais... Netherlands, 2002, p. 306-313.

van de VEIRE, M.; SMAGGHE, G.; DEGHEELE, D. Laboratory test method to evaluate the effect of 31 pesticides on the predatory bug, Orius laevigatus (Heteroptera: Anthocoridae). Entomophaga, Paris, v.41, n.2, p.235-243, 1996. 